\title{
Biochemical and Functional Characterization of Xenoreactive Natural Antibodies in hu-PBL-SCID Mice
}

\author{
Bashoo Naziruddin, Ryoichi Shiroki, Seiichiro Shishido, Todd Howard, and T. Mohanakumar \\ Departments of Surgery and Pathology, Washington University School of Medicine, St. Louis, Missouri 63110
}

\begin{abstract}
An in vivo model system to understand the mechanism of xenograft rejection was established using human peripheral blood leukocyte-reconstituted SCID (hu-PBL-SCID) mice. Human xenoreactive natural antibodies (XNA), of IgM and IgG subtypes, capable of binding to pig aortic endothelial cells (PAEC) were detected in the sera of hu-PBL-SCID by ELISA and flowcytometric methods. Western blot analysis of PAEC lysates showed that IgM and IgG XNA from huPBL-SCID recognized xenoantigens with similar molecular mass as those recognized by XNA from normal human serum (NHS). This result demonstrated that hu-PBL-SCID contained XNA representing the same repertoire as that of the NHS. XNA from NHS and hu-PBL-SCID were also able to induce intracellular $\mathrm{Ca}^{2+}$ signals in cultured PAEC several fold above the basal level. This result revealed their functional similarity and demonstrated for the first time that XNA in the absence of $\mathrm{C}$ can activate PAEC, which may lead to the pathology of xenograft rejection. In vivo, PAEC transplanted under the kidney capsule of hu-PBLSCID mice showed deposition of human IgM and mouse C. In summary, the present study demonstrates that hu-PBLSCID can serve as a useful model to characterize innate immunity against xenograft. (J. Clin. Invest. 1996. 97:12671275.) Key words: transplantation • hu-PBL-SCID • xenoreactive natural antibodies $\bullet$ xenograft $\bullet$ innate immunity
\end{abstract}

\section{Introduction}

Transplantation of solid organs from nonhuman donors (xenograft) into humans has gained increased attention due to the shortage of suitable allografts. Even though transplantation from closely related species like baboons or chimpanzees (concordant) into humans can be accomplished with limited success, ethical and medical problems associated with procuring such organs have rendered it impractical. Successful transplantation of solid organs between discordant species (for example,

Address correspondence to T. Mohanakumar, Department of Surgery, Box 8109, CSRB 4449, Washington University School of Medicine, 4939 Children's Place, St. Louis, MO 63110. Phone: 314-3628463; FAX: 314-362-4647.

Ryoichi Shiroki's present address is Department of Urology, Fujita Health University School of Medicine, Toyoake, Aichi, Japan.

Received for publication 18 August 1995 and accepted in revised form 8 December 1995.

J. Clin. Invest.

(C) The American Society for Clinical Investigation, Inc. 0021-9738/96/03/1267/09 \$2.00

Volume 97, Number 5, March 1996, 1267-1275 pig to human) may overcome problems associated with organ procurement. However, it will require further understanding of immunological consequences of such xenograft. Vascularized xenografts between discordant species undergo hyperacute rejection $(\mathrm{HAR})^{1}$ mediated by naturally occurring xenoreactive antibodies (XNA) and $\mathrm{C}$ within minutes after implantation $(1,2)$. These rejected xenografts reveal interstitial hemorrhage and edema, intravascular coagulation, and separation of endothelial cells from the underlying matrix (3). The prominent epitope recognized by human XNA is a disaccharide Gal $\alpha(1-3)$ Gal expressed as an integral part of several cell surface glycoprotein and glycolipid structures $(4,5)$.

Several approaches have been initiated toward avoiding the hyperacute rejection. These include: $(a)$ depletion of donor XNAs by perfusion through a xenogeneic organ before transplantation (6-8); (b) depletion of donor XNA by treatment with anti- $\mu$ antibodies (9); (c) administration of soluble CR1 (CD35) which inhibits both classical and alternate pathways of complement activation (10); and $(d)$ creation of transgenic animals (for example pigs) expressing species-specific complement activation regulatory proteins including human membrane cofactor protein (MCP or CD46), decay accelerating factor (DAF or CD55), and CD59 $(11,12)$. Despite this significant progress in overcoming humoral immune response, rejection of vascularized discordant xenogeneic organs could inevitably take place through cell-mediated recognition of xenogeneic antigens. Several in vitro studies have demonstrated the ability of human T cells to recognize, directly or indirectly, xenogeneic targets (13-15). However, no significant progress has been made in this direction due to the lack of an appropriate model to study the humoral and cellular immune response to xenografts.

Transplantation of human lymphoid cells into severe combined immunodeficient mice (hu-PBL-SCID) has resulted in the development of new strategies to study tumor biology (16), autoimmunity $(17,18)$, infectious diseases $(19,20)$, and human hematopoiesis (21-27). Recently we have described a hu-PBLSCID model developed by booster injection of anti-CD3 antibody-stimulated human lymphocytes given $2 \mathrm{~d}$ after the initial injection of PBL (28). Mice reconstituted with this technique were able to reject human islet allografts transplanted beneath the kidney capsule. In the present study we explore the usefulness of hu-PBL-SCID model to study the immune response against a xenograft. Our results show that hu-PBL-SCID produce natural antibodies reactive with xenoantigens that are very similar biochemically and functionally to XNA found in normal human serum (NHS).

1. Abbreviations used in this paper: $\left[\mathrm{Ca}^{2+}\right]_{i}$, intracellular $\mathrm{Ca}^{2+}$ concentration; HAR, hyperacute rejection; NHS, normal human serum; PAEC, pig aortic endothelial cells; XNA, xenoreactive natural antibodies. 


\section{Methods}

$H u-P B L-S C I D$ Mice. SCID mice were engrafted with human peripheral blood mononuclear cells (PBMC or PBL) as described earlier (28). Briefly, human PBMC $\left(30 \times 10^{6}\right)$ isolated by Ficoll-Paque (Pharmacia, Alameda, CA) density gradient centrifugation were suspended in $0.5 \mathrm{ml}$ PBS and injected intraperitoneally in SCID mice. In addition, PBMC were cultured in $100 \mathrm{ng} / \mathrm{ml}$ OKT3 (anti-CD3 mAb; Ortho Diagnostic Systems Inc., Raritan, NJ) containing RPMI 1640 medium supplemented with $25 \mathrm{mM}$ Hepes, $2 \mathrm{mM}$ L-glutamine, $100 \mathrm{U} / \mathrm{ml}$ penicillin, $100 \mathrm{U} / \mathrm{ml}$ streptomycin, and $15 \%$ heat-inactivated human serum for $2 \mathrm{~d}$ at $37^{\circ} \mathrm{C} .10 \times 10^{6} \mathrm{OKT} 3$-stimulated cells were given intraperitoneally $2 \mathrm{~d}$ after the initial injection. Establishment of the chimera was monitored by $(a)$ measurement of human Ig by ELISA, $(b)$ PCR-based detection of human cells in SCID periphery, and (c) flowcytometric analysis of human cell populations (28).

Primary culture of pig aortic endothelial cells (PAEC). Endothelial cells were isolated from pig aorta following the procedure described by Ryan et al. (29) and cultured in Falcon Primaria flasks (Becton Dickinson Co., Lincoln Park, NJ) in RPMI 1640 medium containing 20\% FBS, endothelial cell growth supplement (Collaborative Biochemicals Inc., Bedford, MA), and heparin. PAECs used in this study were in between 5 and 10 passages. The identity of endothelial cells was established by their morphology and acetylated LDL intake.

ELISA for the detection of XNAs. Human XNAs directed against PAEC membrane antigens were detected by a specific ELISA method described earlier (30). Briefly, endothelial cells cultured to confluency in 96-well microtiter plates were fixed with cold $0.01 \%$ glutaraldehyde for $5 \mathrm{~min}$ at $4^{\circ} \mathrm{C}$. After washing with PBS, the wells were blocked with $1 \%$ BSA at room temperature for $1 \mathrm{~h}$. Serial dilutions of heat-inactivated normal human serum (RJO Biologicals, Kansas City, MO), sera from SCID, and sera from Hu-PBL-SCID mice were added to the wells and incubated for $1 \mathrm{~h}$ at room temperature. Binding of human antibodies was detected by alkaline phosphatase-conjugated goat anti-human IgM ( $\mu$-specific; 1:1,000 dilution; Jackson Immunosearch Laboratories, West Grove, PA) or IgG (Fc specific; 1:1,000 dilution) for $1 \mathrm{~h}$ at room temperature. The color was developed using $p$-nitrophenylphosphate as substrate.

Immunofluorescence and flow cytometry. Human XNAs directed against PAEC were also detected by immunofluorescence followed by flow cytometry using a FACScan Analyzer (Becton Dickinson) equipped with a single argon-ion laser. Primary cultured PAEC $\left(5 \times 10^{5}\right.$ cells) in HBSS containing $0.1 \%$ sodium azide, $20 \mathrm{mM}$ Hepes, and 2 mM EDTA were initially blocked with $10 \%$ normal goat serum for 30 min at $4^{\circ} \mathrm{C}$. After washing (twice) with HBSS containing $1 \%$ goat serum, the cells were incubated with the first antibody (NHS or serum from SCID or hu-PBL-SCID) for $60 \mathrm{~min}$ at $4^{\circ} \mathrm{C}$. Cells were washed twice, treated with FITC-conjugated goat anti-human IgM ( $\mu$-specific) or $\mathrm{IgG}$ (Fc-specific) for $30 \mathrm{~min}$ at $4^{\circ} \mathrm{C}$. After washing twice, cells were gated by forward scatter and side scatter parameters on the FACScan. Data were collected on 3,000 cells with fluorescence logarithmic amplification and analyzed with LYSYS software.

Serum absorption experiments were done to further define the antigens recognized by human XNA. NHS or hu-PBL-SCID serum samples were incubated with cytoskeletal proteins (equimolar concentrations of actin and tubulin; Sigma Chemical Co., St. Louis, MO), or thyroglobulin or double-stranded DNA (ssDNA) or Fc fraction of human Ig at $1 \mathrm{mg} / \mathrm{ml}$ concentration for $3 \mathrm{~h}$ at $4^{\circ} \mathrm{C}$. After incubation, the samples were centrifuged at 110,000 $g$ and the supernatant was used for Western blot and FACS analysis.

For monitoring in vivo binding of XNA to PAEC, $2 \times 10^{6}$ viable cells were engrafted under the kidney capsule (28). Kidneys, harvested $3 \mathrm{~d}$ after transplant, were embedded in OCT compound (Lab Tek Products, Naperville, IL) and cut into 4-6 $\mu \mathrm{m}$ sections. Tissue sections were mounted on poly-L-lysine-coated slides and were either used immediately or kept frozen at $-70^{\circ} \mathrm{C}$ until analysis. The slides were fixed with $100 \%$ methanol and washed with PBS followed by blocking with $2 \%$ fishgel. Subsequently the slides were stained with (a) biotinylated mAb 74.11.10 (anti-pig class I; American Type Culture Collection, Rockville, MD) followed by avidin-peroxidase detection system, (b) FITC-conjugated anti-human IgM, and $(c)$ with FITC-conjugated anti-mouse C3.

Western blotting. PAEC or human umbilical vein endothelial cells at $10 \times 10^{6} / \mathrm{ml}$ were lysed at $4^{\circ} \mathrm{C}$ for $1 \mathrm{~h}$ in PBS containing $0.5 \%$ octylglucoside and protease inhibitors ( $2 \mathrm{mM}$ PMSF, $5 \mu \mathrm{g} / \mathrm{ml}$ aprotinin, $10 \mu \mathrm{g} / \mathrm{ml}$ leupeptin, $10 \mu \mathrm{g} / \mathrm{ml}$ pepstatin). After centrifugation at $100,000 \mathrm{~g}$ for $30 \mathrm{~min}$, supernatant protein concentration was determined by BCA method (Pierce, Rockford, IL). $50 \mu \mathrm{g}$ of supernatant protein was loaded per well on a 5-15\% SDS-polyacrylamide gel and subjected to electrophoresis followed by electroblotting on to Immobilon-P membrane. The membranes were initially blocked with $3 \%$ BSA and subsequently probed with the appropriate dilution of NHS, SCID, or hu-PBL-SCID sera followed by alkaline phosphatase-conjugated anti-human IgM or IgG (Organon Teknika Corp., Durham, NC) or anti-swine IgM (Kirkegaard \& Perry Laboratories Inc., Gaithersburg, MA), and color was developed with 5-bromo-4-chloro3-indolyl phosphate and nitro blue tetrazolium substrates (Sigma Chemical Co.).

Intracellular $\mathrm{Ca}^{2+}$ concentration measurement in $P A E C$. Changes in intracellular $\mathrm{Ca}^{2+}$ concentration $\left(\left[\mathrm{Ca}^{2+}\right]_{\mathrm{i}}\right)$ were measured after XNA stimulation in cultured PAEC loaded with the $\mathrm{Ca}^{2+}$-specific fluorescent probe indo 1-AM (Molecular Probes, Eugene, OR). Briefly, PAEC were cultured in glass-bottomed petri dishes (Mat Tek, Ashland, MA) and loaded with $10 \mu \mathrm{M}$ indo 1-AM dissolved in $0.02 \%$ DMSO and pluronic as a dispersing agent. After 30-min incubation with indo 1-AM, the cells were washed and kept in HBSS (with or without $\mathrm{Ca}^{2+}$ and $\mathrm{Mg}^{2+}$ ). XNA from $25 \mu$ of normal human serum or $100 \mu \mathrm{l}$ of serum from SCID or hu-PBL-SCID were added to the indo-1 loaded PAEC and the fluorescent changes were measured using a laser scanning confocal microscope equipped with argon laser and a water immersion $\times 40$ fluor objective (RCM 8000; Nikon Inc., Melville, NY). Indo-1 is a dual emission dye and when excited at 354 $\mathrm{nM}$ two wavelengths are emitted, i.e., a wavelength at $405 \mathrm{nM}$ corresponding to indo- 1 bound to $\mathrm{Ca}^{2+}$ and a wavelength at $480 \mathrm{nM}$ corresponding to free indo-1. Two photo multipliers simultaneously detect both emission wavelengths, and the analog signals are then digitized, ratioed, and displayed in color as high resolution spatial concentration images. For calibration, the intensities of test solutions of $\mathrm{Ca}^{2+}$ varying from 0 to $1 \mathrm{mM}$ were determined with $5 \mu \mathrm{M}$ pentapotassium indo- 1 . The ratiometric calculations were done using the method described by Grynkiewicz et al. (31).

\section{Results}

Detection of XNA in Hu-PBL-SCID sera by ELISA. One of the goals of this work is to evaluate hu-PBL-SCID mice as a model to study human immunologic reaction toward a clinically relevant discordant xenograft, for example, porcine grafts. Since endothelial cell lining of the xenograft is the major site of attack during HAR, we used PAEC as the antigenic source to evaluate human XNA. Initially we examined for the presence of XNA in the sera of chimeric hu-PBL-SCID mice which were established based on our earlier protocol (28). The concentration of human Ig in these mice was 1,143.9 \pm 325.4 $\mu \mathrm{g} / \mathrm{ml}$ when measured 7-9 wk after initial injection of human lymphocytes. Sera from the hu-PBL-SCID were analyzed by ELISA (30) for XNA capable of binding to cultured PAEC. Using secondary antibody conjugates specific for both human $\operatorname{IgM}$ ( $\mu$ chain specific) and IgG (Fc specific), we were able to detect both IgM (Fig. $1 A$ ) and IgG (Fig. $1 B$ ) subtypes of XNA in the sera of hu-PBL-SCID. Sera samples from plain SCID mice did not contain PAEC-specific XNA. Porcine se- 

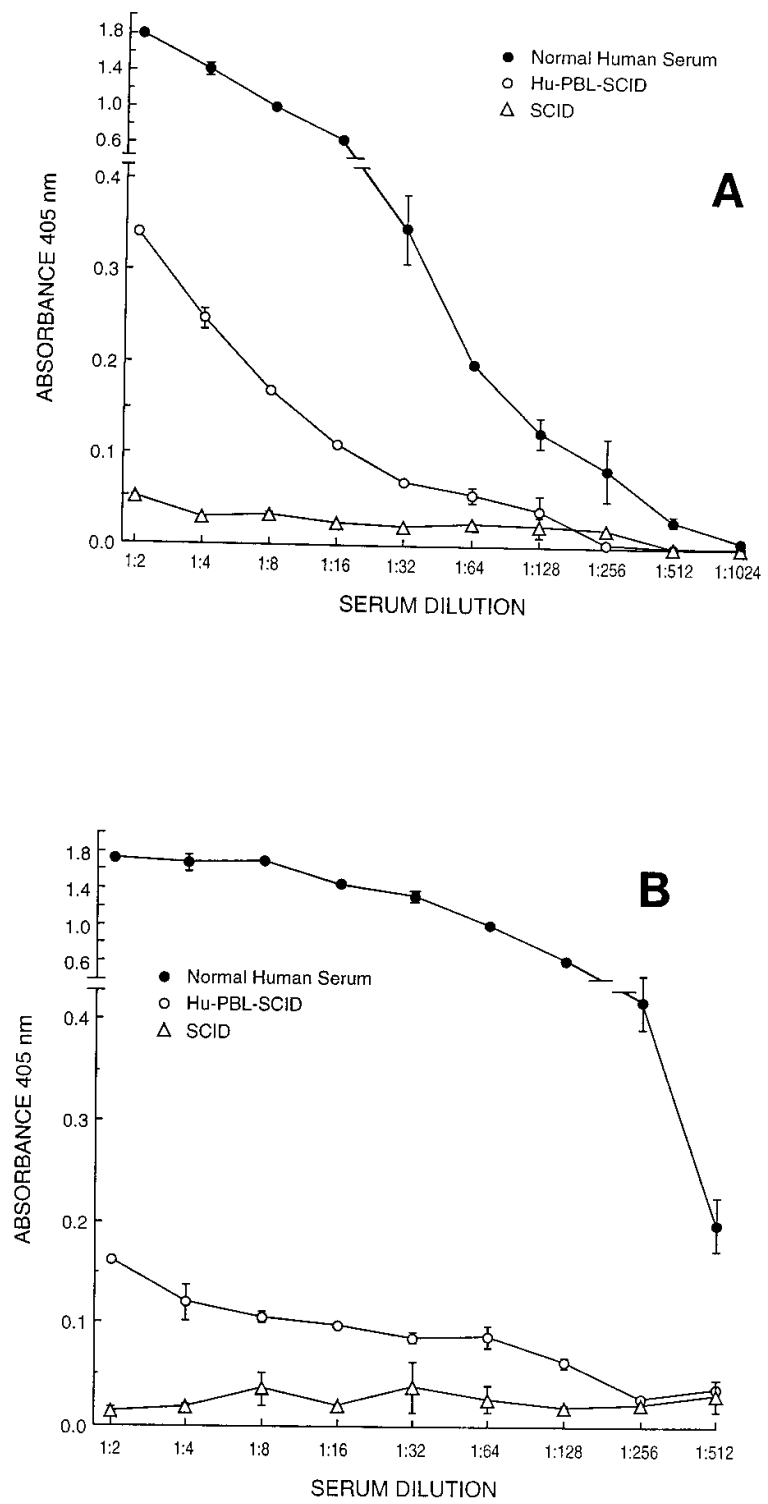

Figure 1. ELISA for measurement of XNA present in hu-PBL-SCID sera. PAECs grown to confluency in 96-well flat bottomed culture plate were used as antigen and serially diluted NHS or SCID or sera from hu-PBL-SCID or SCID were added to the wells followed by alkaline phosphatase-conjugated anti-human IgM ( $\mu$-chain specific) $(A)$. Similar detection of $\mathrm{IgG}$ antibodies was made using anti-human $\mathrm{IgG}$ (Fc specific) (B). Experiments on serum samples collected from six hu-PBL-SCID gave similar results. Results from a representative experiment are shown.

rum used as a control showed no reactivity exceeding the background (data not shown). A linear titration of the antibody concentration was observed in case of both hu-PBLSCID and NHS. Earlier studies have shown that hu-PBLSCID contain 10-fold less human Ig when compared to NHS $(26,27)$. Accordingly, lower amounts of XNA reacting to PAEC were seen in hu-PBL-SCID sera when compared to NHS. Our present results also showed that hu-PBL-SCID sera contained more IgM than IgG subtype XNA.

Flow cytometric analysis of XNA binding to PAEC. To further evaluate the nature and binding of XNA present in the
hu-PBL-SCID serum, we used immunofluorescence followed by flow cytometric analysis. As shown in Fig. 2, both $\operatorname{IgM}(A)$ and $\operatorname{IgG}(B)$ subtype XNA binding to PAEC were detected. In accordance with ELISA data: $(a)$ a lower quantity of hu-PBLSCID XNA was detected when compared to NHS; $(b)$ huPBL-SCID XNA consisted primarily of IgM type antibodies; and $(c)$ no XNAs were detected in the plain SCID serum using flow cytometric analysis.

Western blot analysis of antigens recognized by XNA present in the hu-PBL-SCID serum. Previous studies on XNA have shown that the antibodies predominantly recognize a Gal $\alpha(1-3)$ Gal epitope expressed on several glycoprotein and glycolipid structures of the cell membrane (4). To test whether XNA present in the hu-PBL-SCID recognize identical xenoantigens as the NHS XNA, we probed Western blots of PAEC cell lysates $(50 \mu \mathrm{g}$ of protein was uniformly loaded per lane) with NHS and sera from SCID or hu-PBL-SCID. As shown in Fig. $3 A$, IgM type XNA present in both NHS and hu-PBL-SCID serum essentially recognized similar xenoantigens. The molecular mass of common xenoantigens recognized by IgM type antibodies were 250, 174, 150, 110, 83, 52, 47, 39, and $30 \mathrm{kD}$. Similarly the molecular mass of the common xenoantigens recognized by $\mathrm{IgG}$ type antibodies were 128,106 , $48,40,28$, and $21 \mathrm{kD}$ (Fig. $3 \mathrm{~B}$ ). Sera from plain SCID failed to recognize any xenoantigens in these Western blots. XNA from

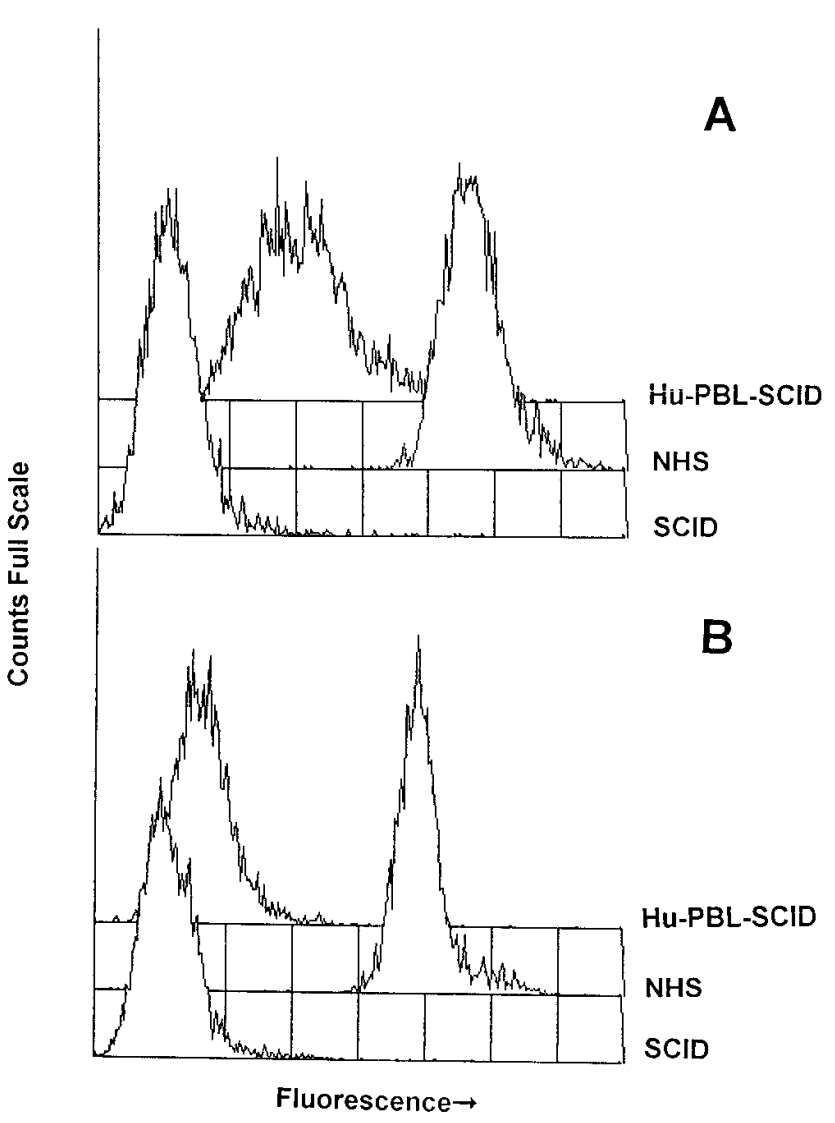

Figure 2. FACS analysis of human XNAs directed against PAEC. Normal human serum (1:50 dilution) or serum from SCID (1:5 dilution) or hu-PBL-SCID (1:5 dilution) were treated with PAEC and the bound XNAs were detected using FITC-conjugated anti-human IgM $(A)$ or $\operatorname{IgG}(B)$. Results are representative of three independent experiments. 


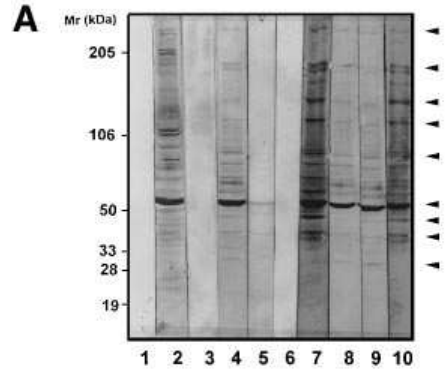

B

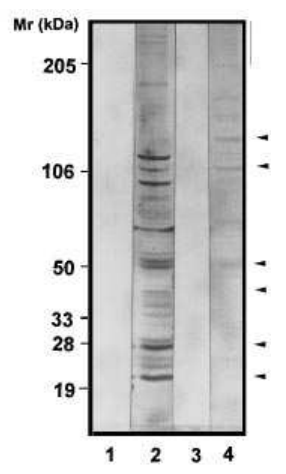

Figure 3. Western blot analysis of antigens recognized by human XNAs present in NHS and hu-PBL-SCID serum. PAEC lysates (50 $\mu \mathrm{g}$ of protein per lane; Lanes 1-4 and 6-10) were separated on 5-15\% gradient SDS-PAGE and analyzed by Western blotting for human XNAs of $\operatorname{IgM}(A)$ or $\operatorname{IgG}(B)$ isotype. Lane 1: secondary antibody alone; lane 2: NHS (1:100 dilution); lane 3: SCID serum (1:10 dilution); lane 4: hu-PBL-SCID serum (1:10 dilution); lane 5: $50 \mu \mathrm{g}$ of human umbilical vein endothelial cell lysate protein probed with huPBL-SCID serum (1:10 dilution); lane 6: pig serum (1:100 dilution); lane 7: hu-PBL-SCID serum absorbed with actin and tubulin; lane 8 : hu-PBL-SCID serum absorbed with thyroglobulin; lane 9: hu-PBLSCID serum absorbed with ssDNA; and lane 10: hu-PBL-SCID serum absorbed with $\mathrm{Fc}$ fraction of IgG. In $A$ all lanes except lane 6 were probed with 1:1,000 diluted alkaline phosphatase-conjugated goat anti-human IgM while lane 6 was probed with alkaline phosphatase-conjugated goat anti-swine IgM. In $B$ the membranes were probed with 1:1,000 diluted goat anti-human IgG. The color development was performed with 5-bromo-4-chloro-3-indolyl phosphatenitro blue tetrazolium substrates.

NHS showed recognition of more antigens than did XNA from hu-PBL-SCID. This was more apparent in the case of IgG subtype XNA. This could be due to differences in the concentration of XNA and also due to the fact that NHS used in this study is pooled serum when compared to hu-PBL-SCID serum representing a single individual. Overall, this result revealed that XNA repertoire in hu-PBL-SCID is representative of NHS XNA. Some of the antigens recognized by XNA are well characterized. For example, the $250-\mathrm{kD}$ band could correspond to the vWf as reported earlier (32). The bands corresponding to molecular mass between 100 and $150 \mathrm{kD}$ could be the integrin type xenoantigens (32). The exact identity of the xenoantigens observed in these western blot remains to be elucidated.

To distinguish the antigenic specificity of the XNA observed in hu-PBL-SCID serum from the autoreactive naturally occurring antibodies which were reported earlier (33-36), the following experiments were performed: In the Western blot experiments, human endothelial cells lysate proteins were run at equal concentration to that of PAEC lysate (Fig. $3 \mathrm{~A}$, lane 5 ). The hu-PBL-SCID serum showed recognition of only 52and $39-\mathrm{kD}$ bands thus revealing that the other major bands recognized in PAEC lysate are xenogeneic in nature. Secondly, pig serum was treated with PAEC lysate in these Western blots followed by anti-swine IgM antibody conjugate (Fig. $3 \mathrm{~A}$, lane 6 ). This detected no bands indicating that porcine autoantigens are not recognized by human XNA. Thirdly, four of the common autoantigens reported to react with naturally occurring antibodies, namely, cytoskeletal proteins (actin and tu- bulin), thyroglobulin, ssDNA, and $\mathrm{Fc}$ fraction of $\mathrm{IgG}$ were treated with NHS or hu-PBL-SCID serum for $3 \mathrm{~h}$ at $4^{\circ} \mathrm{C}$ before Western blot and FACS analysis. Western blot experiments (Fig. 3 A, lanes 7-10) showed no major differences indicating that the xenoantigens observed in these experiments are different from the autoantigens. Since the four autoantigens tested in the western blot experiments have major variation in terms of their molecular mass (for example $675,000 \mathrm{D}$ for thyroglobulin and 43,000 D for actin) which could not be separated on the same polyacrylamide gel, the ability of these autoantigens to block the binding of human XNA to PAEC was tested by immunofluorescence and FACS analysis. As shown in Fig. 4, all the four autoantigens tested blocked the binding of human XNA from NHS and hu-PBL-SCID by 15-35\%, revealing the polyreactive nature of XNA present in NHS and hu-PBL-SCID. These results also indicated that majority of XNA are directed against porcine xenoantigens.

Intracellular $\mathrm{Ca}^{2+}$ mobilization in cultured PAEC by XNA. Since recent reports $(32,37)$ have identified some of the xenoantigens as integrins which are known to be signal transducing receptors, we determined elevation of $\left[\mathrm{Ca}^{2+}\right]_{\mathrm{i}}$ in PAEC after the binding of XNA. PAEC loaded with $\mathrm{Ca}^{2+}$ selective fluorescent indicator dye indo-1 were treated with heat-inactivated NHS or sera from hu-PBL-SCID or SCID. Using the confocal microscope, we were able to accurately monitor the $\left[\mathrm{Ca}^{2+}\right]_{\mathrm{i}}$ changes at a single cell level. As shown in Fig. $4 \mathrm{~A}$, the binding of XNA from NHS to PAEC in the absence of crosslinking and $\mathrm{C}$, induced an approximately fourfold transient in-

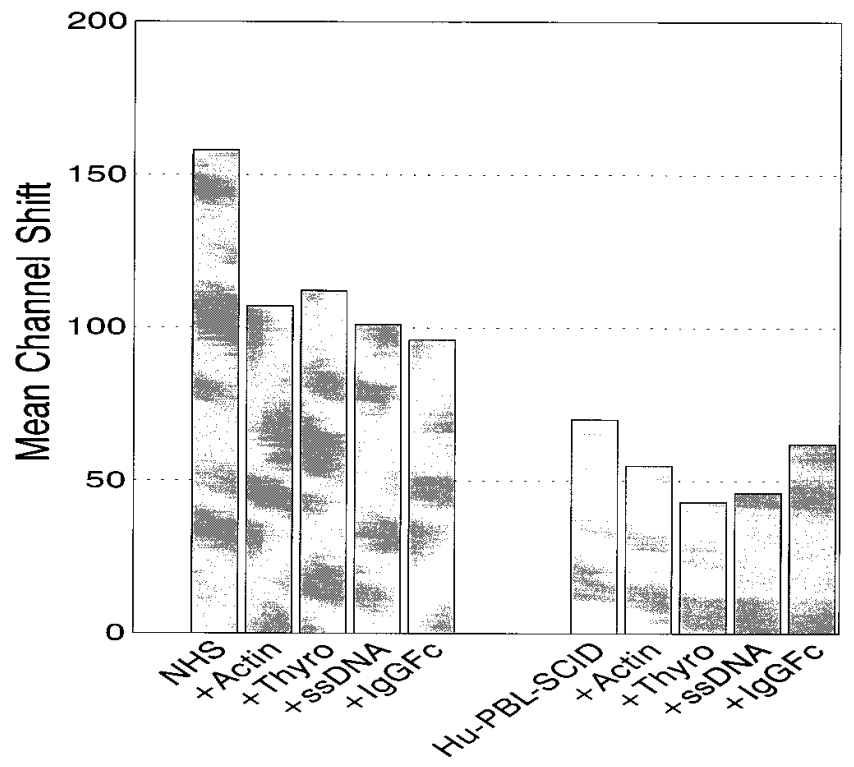

Figure 4. FACS analysis of antigenic specificity of XNA present in NHS and hu-PBL-SCID serum. Normal human serum (1:50 dilution) or hu-PBL-SCID serum (1:5 dilution) were incubated with $1 \mathrm{mg} / \mathrm{ml}$ each of cytoskeletal proteins (actin and tubulin) or thyroglobulin (Thyro) or ssDNA or Fc fraction of human IgG for $3 \mathrm{~h}$ at $4^{\circ} \mathrm{C}$ and centrifuged at 110,000 $\mathrm{g}$ for $30 \mathrm{~min}$ and the supernatant was added to PAEC. The bound XNAs were detected using FITC-conjugated antihuman IgM. Results are representative of three independent experiments and are expressed as mean channel shift comparing the fluorescence of cells stained with XNA to the fluorescence of staining with secondary antibody alone. 
crease in $\left[\mathrm{Ca}^{2+}\right]_{\mathrm{i}}$ over the basal level. XNA from hu-PBLSCID also induced an approximately twofold increase in $\left[\mathrm{Ca}^{2+}\right]_{\mathrm{i}}$ (Fig. $4 \mathrm{~B}$ ), while the serum from SCID did not induce an increase (data not shown). These studies demonstrate for the first time in vitro that XNA can activate endothelial cells, which involves a $\mathrm{Ca}^{2+}$ signal. Interestingly, the presence of EGTA in the buffer abrogated the increase in $\left[\mathrm{Ca}^{2+}\right]_{\mathrm{i}}$ (Fig. 4 $C$ ) suggesting that most of the increase in $\left[\mathrm{Ca}^{2+}\right]_{\mathrm{i}}$ could be due to the influx from the extracellular origin through the $\mathrm{Ca}^{2+}$ channels.

$X N A$ from hu-PBL-SCID bind to PAEC transplanted under the kidney capsule. The studies described so far represent an in vitro analysis of the XNA from hu-PBL-SCID mice. To further extend the in vivo relevance of hu-PBL-SCID model in studying the human immunological reaction to porcine xenograft, we transplanted $2 \times 10^{6}$ viable PAECs under the kidney capsule of hu-PBL-SCID. After $3 \mathrm{~d}$ post-transplant to establish vasculature under the kidney capsule of the Hu-PBLSCID, the kidney was harvested and stained for the binding of human XNA. To distinguish the PAEC from mouse kidney cells, the tissue sections were stained with anti-porcine class I $\mathrm{mAb} 74.11 .10$. Fig. $5 A$ shows the deposition of human IgM on PAEC, an important immunohistological feature of HAR. Staining with anti-porcine class I (Fig. 5 B) showed that PAEC transplanted under the kidney maintained their morphology. In a separate experiment the PAEC placed under the kidney capsule of hu-PBL-SCID mice were stained for mouse C3. As shown in Fig. $5 C$, the PAEC also showed deposition of mouse C3, another mediator of HAR. However, antibody-mediated cytotoxicity of PAEC was not observed in these experiments. This could be due to the inability of mouse $\mathrm{C}$ to effectively bring out the lysis of the PAEC. To test this, $0.5 \mathrm{ml}$ of fresh pig serum, as a source of $\mathrm{C}$, was injected intraperitoneally in the hu-PBL-SCID mice which engrafted with PAEC under the kidney capsule. After $3 \mathrm{~h}$, the kidneys were harvested and stained for PAEC and anti-human IgM. The tissue sections showed complete disintegration of PAEC placed under the kidney capsule (data not shown) further confirming that HAR can take place in this model.

\section{Discussion}

Following the report by Mosier et al. (26) on the engraftment of human lymphocytes in SCID mice, several laboratories have reported the usefulness of the hu-PBL-SCID model to investigate a diverse range of human diseases including cancer, autoimmune, infectious diseases, and lymphomagenesis (1627). The functional interaction of human $T$ and $B$ cells in these chimeric animals is intact based on antigen dose-dependent humoral response to tetanus toxoid (38) and keyhole lympet hemocyanin $(39,40)$. The major limitation of this model is thought to be the existence of mouse natural killer cells which down-regulate the effectiveness of human PBL chimera establishment (27). Earlier we reported on establishing hu-PBLSCID chimera effectively by the booster injection of anti-CD3 antibody-stimulated human lymphocytes (28). In the present report, we have focused on the usefulness of the hu-PBLSCID model to study human immune response to clinically relevant porcine xenograft. Since the xenograft endothelium is a major site of interaction between the host immune system and the solid organ, we analyzed the development and func- tion of human XNA recognizing PAEC antigens in this huPBL-SCID model.

Our results using ELISA and flowcytometric methods have conclusively shown the existence of human XNA in the sera of hu-PBL-SCID against xenoantigens expressed on PAEC. The XNA were of both IgM and IgG subtypes. These results are consistent with earlier reports showing the presence of all four subclasses of $\operatorname{IgG}$, as well as $\operatorname{IgM}$, IgA, IgD, and/or IgE in huPBL-SCID mice (41-43). In the porcine to primate xenotransplantation model, it is thought that XNA of IgM isotype are critical because they can effectively fix C $(44,45)$. Hence several studies have focused on the antigens recognized by only IgM type XNA $(46,47)$. However, the presence of XNA of IgG had also been observed $(48,30)$, and they are thought to play a role in the xenotransplant rejection.

Western blot analysis of PAEC antigens recognized by XNA of IgG and IgM subtypes from hu-PBL-SCID and also from NHS showed that several antigens of molecular mass in the range of $20-250 \mathrm{kD}$. Studies by Platt and co-workers (44, 46,49 ) have emphasized the importance of 115-, 135-, and 150$\mathrm{kD}$ high molecular mass glycoproteins recognized by IgMXNA and have identified them as members of integrin family. The $250-\mathrm{kD}$ band has been recognized as vWF. On the other hand, two other studies $(45,50)$ have also shown the presence of low molecular mass xenoantigens recognized by human XNA. The biochemical nature of these low molecular mass antigens is not clearly identified at present. Our results also show that a broad XNA repertoire is present in the hu-PBL-SCID which recognizes a wide range of xenoantigens.

We also attempted to delineate the nature of the antigens recognized by XNA as compared to autoantigens reported earlier (33-36). We used all the major autoantigens used in previous studies including cytoskeletal proteins like actin and tubulin, thyroglobulin, ssDNA, and IgG Fc fractions. Our Western blot results indicated no major differences after blocking of sera with autoantigens. Thus, the xenoantigens observed in this study are different from the autoantigens reported earlier $(33,34)$. However partial blocking of XNA binding by autoantigens could not be distinguished by the Western blot technique. On the other hand, FACS analysis clearly showed that some of the XNA described in the present study are cross-reactive to these autoantigens tested. This could be due to polyreactive nature of XNA which primarily recognize Gal $\alpha(1-3)$ Gal epitope expressed on several glycoprotein structures including thyroglobulin $(4,5)$. Interestingly, XNA present in the hu-PBL- SCID serum were blocked to the same extent as that of XNA from the NHS except in the case of IgG Fc fraction.

Earlier reports have suggested that human $\mathrm{XNA}$ are the products of peripheral blood CD5+ B cells $(51,52)$ leading to the speculation that engraftment of human PBL into SCID mice will result in selective expansion of these clones. Our Western blot analysis of hu-PBL-SCID serum versus NHS showed some differences: hu-PBL-SCID sera reacted to some but not all protein identified by NHS. This can be explained by either selective expansion of certain CD5+ B cells or due to the fact that hu-PBL-SCID serum represented an individual sample when compared pooled NHS used in this study. Recent studies by Parker et al. (53) have shown that human XNAs present in NHS are polyreactive natural antibodies having limited diversity and the same or similar antibodies are shared widely in the population. This may also account for the varia- 

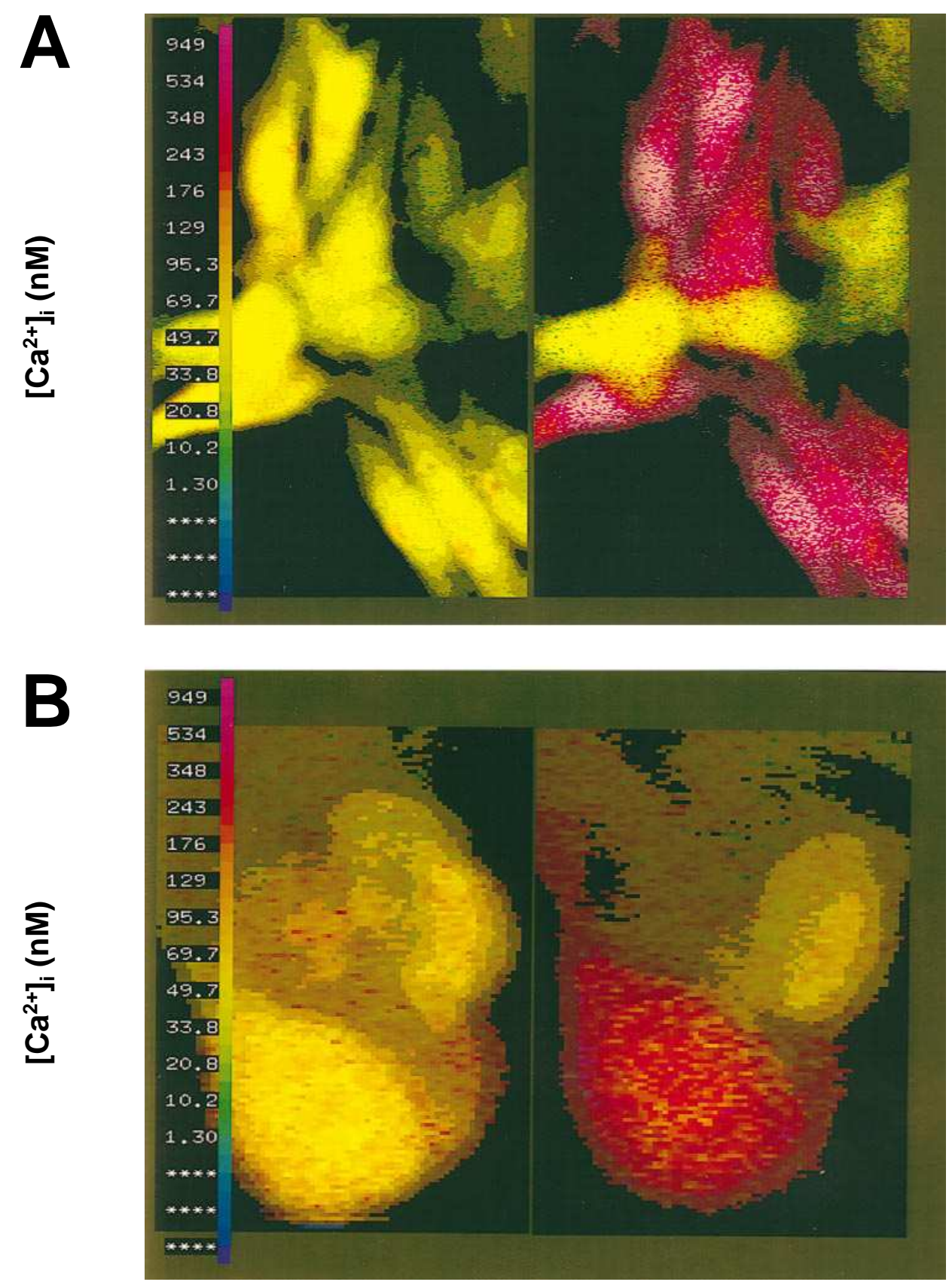

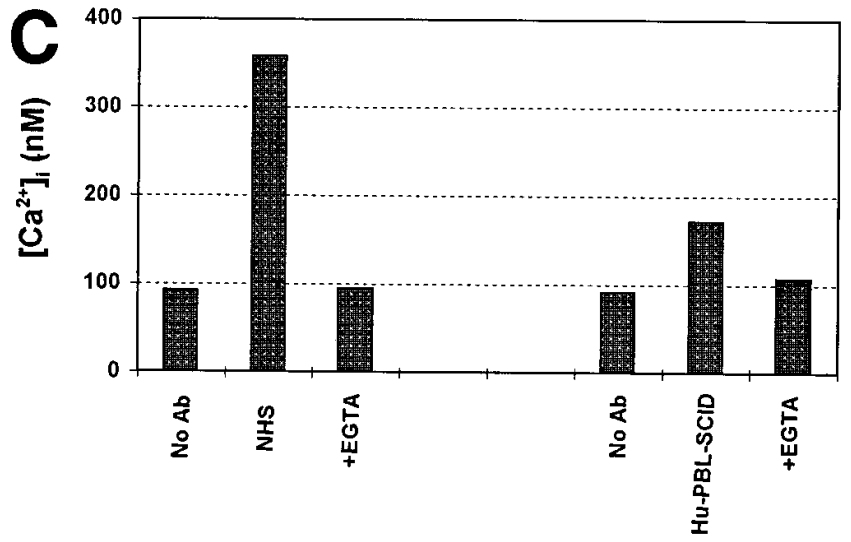

Figure 5. Intracellular $\mathrm{Ca}^{2+}$ mobilization in PAEC by XNA from NHS $(A)$ and sera from hu-PBL-SCID $(B)$. PAEC were cultured on special glass-bottomed petri dishes and loaded with indo-1 AM as described in Methods. After addition of $10 \mu \mathrm{l}$ of NHS or $100 \mu \mathrm{l}$ of hu-PBL-SCID serum, the change in the fluorescent emission ratio of the free and calcium bound indo- 1 were recorded, and $\left[\mathrm{Ca}^{2+}\right]_{i}$ was calculated as described (31). $\left[\mathrm{Ca}^{2+}\right]_{\mathrm{i}}$ scale in $\mathrm{nM}$ concentration is shown on the left. The left panel shows cells at basal level $\left[\mathrm{Ca}^{2+}\right]_{\mathrm{i}}$ and the right panel shows the peak level at $60 \mathrm{~s}$ after stimulation. $C$ shows the $\mathrm{Ca}^{2+}$ concentrations plotted in the presence or absence of 2 mM EGTA. Results shown are representative of three independent experiments. 

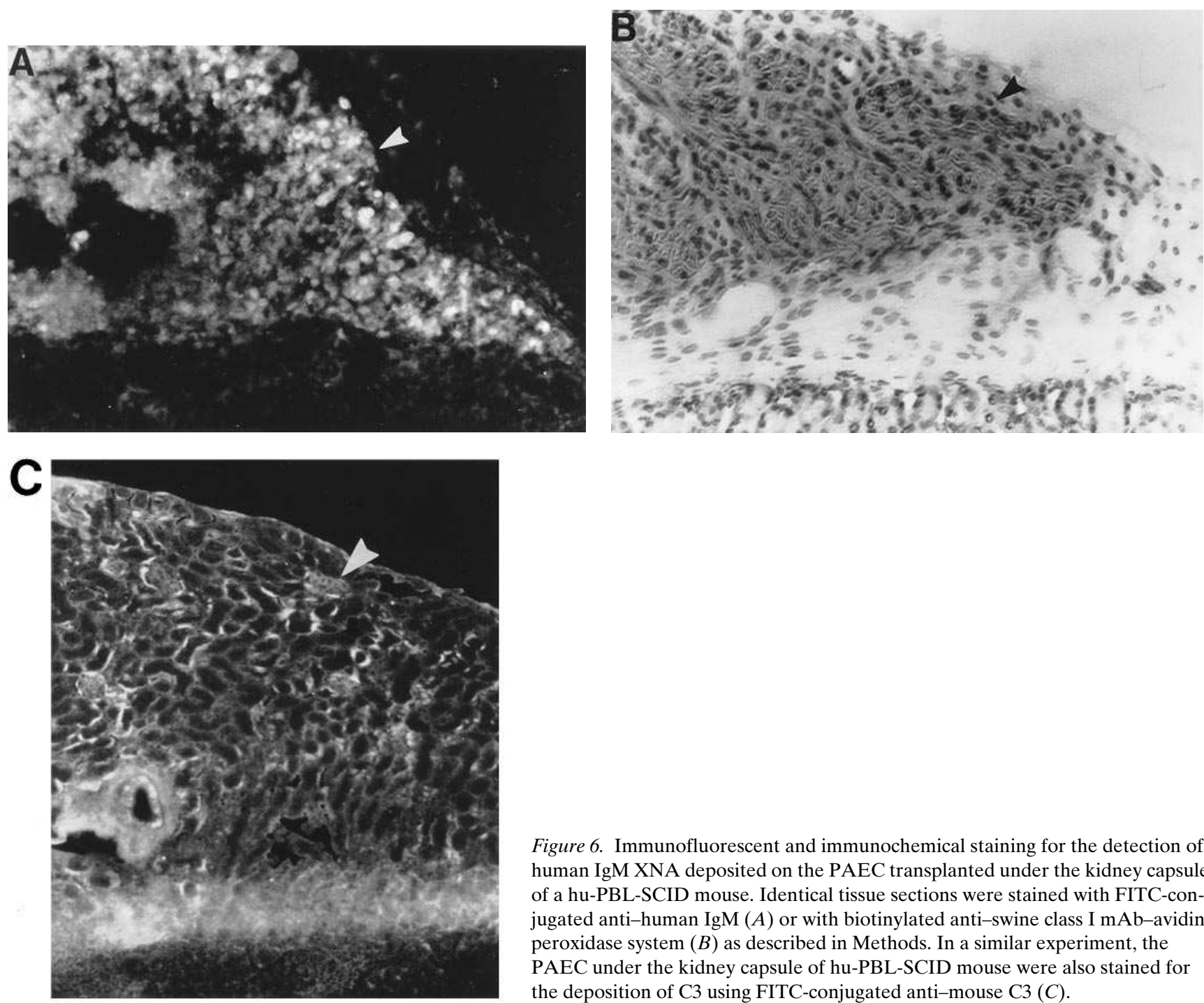

Figure 6. Immunofluorescent and immunochemical staining for the detection of human IgM XNA deposited on the PAEC transplanted under the kidney capsule of a hu-PBL-SCID mouse. Identical tissue sections were stained with FITC-conjugated anti-human $\operatorname{IgM}(A)$ or with biotinylated anti-swine class I mAb-avidin peroxidase system $(B)$ as described in Methods. In a similar experiment, the PAEC under the kidney capsule of hu-PBL-SCID mouse were also stained for the deposition of $\mathrm{C} 3$ using FITC-conjugated anti-mouse $\mathrm{C} 3(C)$.

tions seen in the Western blot recognition by XNA from huPBL-SCID and NHS.

Two types of reactions termed as endothelial stimulation (type I activation) and endothelial activation (type II activation) are hypothesized to take place after the binding of XNA and $\mathrm{C}$ to the endothelial cells (48). A significant part of the hypothesis is that XNA in the presence or absence of $\mathrm{C}$, will deliver a signal leading to in vivo activation of endothelial cells resulting in HAR or delayed xenograft rejection. Studies by Saadi and Platt (54) have shown that human XNA and C cause formation of intercellular gap in PAEC. The formation of gaps was associated with actin-based cytoskeleton and with an increase in the level of cAMP. Our results clearly show that binding of XNA to PAEC induces a transient increase in $\left[\mathrm{Ca}^{2+}\right]_{\mathrm{i}}$ influx. This influx of $\mathrm{Ca}^{2+}$ is from an extracellular source based on the abrogation of this signal by EGTA. These results have shown for the first time that XNA may trigger a $\mathrm{Ca}^{2+}$-dependent signaling pathway in the endothelial cells. This is not surprising since human XNA were found to recognize integrin type molecules on PAEC (32) which have been shown to be signal transducing receptors (55). Activation of PAEC by XNA in the absence of complement could lead to changes in the endothelium resulting in both humoral and cel- lular immune response leading to rejection of the xenograft. In addition, it is likely that such activation could lead to induction of interleukins and other factors which are produced by the endothelial cells, leading to activation of immune system. Further studies on the receptors involved and identification of intracellular signaling molecules activated by the binding of XNA to PAEC should clarify the pathological and biological consequence of such activation.

Our in vivo studies clearly demonstrate the deposition of human IgM along with mouse $\mathrm{C}$ on the PAEC transplanted under the kidney capsule of hu-PBL-SCID. Similar studies conducted on plain SCID showed no binding of XNA (not shown). The PAEC were distinguished from mouse kidney by staining with anti-porcine class I mAb. The immunochemical staining of the PAEC showed that despite the binding of XNA and $\mathrm{C}$, the PAEC did not show cytotoxicity, which is a histological characteristic of xenograft rejection. This could be due to lack of adequate amounts of mouse $\mathrm{C}$ or its inability to mediate cytotoxicity. This prediction was later proven to be correct by injection of an adequate amount of pig $\mathrm{C}$ into these mice, leading to damage of PAECs.

In summary, the studies describing the humoral immune response to xenoantigens outlined in this communication show 
that hu-PBL-SCID promises to be a good model system to study xenoimmune response. This report also shows for the first time that XNA in the absence of $\mathrm{C}$ can induce signal transduction pathways leading to activation of endothelial cells. The usefulness of this model could also be extended to analyze human cellular immune response to a xenograft of choice since the endothelial cells under the kidney capsule were not destroyed in a hyper acute fashion unless extraneous $\mathrm{C}$ was injected into the animals. Our earlier studies (28) using the hu-PBL-SCID model have demonstrated the presence of class I restricted graft-infiltrating cytolytic $\mathrm{T}$ lymphocytes which are capable of rejecting islet allografts. We are currently investigating the kinetics and function of cells infiltrating PAEC placed under the kidney capsule of hu-PBL-SCID mice in the absence of extraneous $\mathrm{C}$. Considering that in vivo PAEC can elicit both a CD8 and CD4 response to xenoantigens it is likely that such cells may infiltrate and mediate in xenograft rejection in hu-PBL-SCID model.

\section{Acknowledgments}

We thank Drs. M. Wayne Flye, Richard Hotchkiss, and Nancy Poindexter for their critical review of the manuscript, Brian F. Duffy for technical assistance, and Mrs. Billie Glasscock for secretarial assistance.

This work was supported by a grant from the National Institutes of Health (R01 AI33551).

\section{References}

1. Auchincloss, H., Jr. 1988. Xenogeneic transplantation: a review. Transplantation (Baltimore). 46:1-20

2. Lu, C.Y., T.A. Khair-el-din, I.A. Dawidson, T.M. Butler, K.M. Brasky, M.A. Vasquez, and S.C. Sicher. 1994. Xenotransplantation. FASEB J. 8:11221130 .

3. Rose, A.G., D.K.C. Cooper, P.A. Human, H. Reichenspurner, and B. Reichart. 1991. Histopathology of hyperacute rejection of the heart: experimental and clinical observations in allografts and xenograft. J. Heart Lung Transplant. 10:223-234.

4. Galili, U. 1993. Interaction of the natural anti-Gal antibody with $\alpha$-galactosyl epitopes: a major obstacle for xenotransplantation in humans. Immunol. Today. 14:480-482.

5. Sandrin, M.S., H.A. Vaughan, P.L. Dabkowski, and I.F.C. McKenzie. 1993. Anti-pig IgM antibodies in human serum react predominantly with Gal( (11-3)Gal epitopes. Proc. Natl. Acad. Sci. USA. 90:11391-11395.

6. Perper, R.J., and J.S. Najarian. 1966. Experimental renal heterotransplantation. Transplantation (Baltimore). 4:377-382.

7. Cooper, D.K.C., P.A. Human, G. Lexer, A.G. Rose, J. Rees, M. Keraan, and E. Du Toit. 1988. Effects of cyclosporine and antibody adsorption on pig cardiac xenograft survival in the baboon. J. Heart Transplant. 7:238-246.

8. Fischel, R.J., A.J. Matas, J.L. Platt, E. Perry, H. Noreen, S.J. Shumway, and R.M. Bolman III. 1992. Cardiac xenografting in the pig to rhesus monkey model: manipulation of anti-endothelial antibody prolongs survival. J. Heart Lung Transplant. 11:965-973.

9. Soares, M.P., D. Latinne, M. Elsen, J. Figueroa, F.H. Bach, and H. Bazin. 1993. In vivo depletion of xenoreactive natural antibodies with an anti- $\mu$ monoclonal antibody. Transplantation (Baltimore). 56:1427-1433.

10. Pruitt, S.K., W.M. Baldwin, III, H.C. Marsh, Jr., S.S. Lin, C.G. Yeh, and R.R. Bollinger. 1991. The effect of soluble complement receptor type 1 on hyperacute xenograft rejection. Transplantation (Baltimore). 52:868-873.

11. White, D., and J. Wallwork. 1993. Xenografting: probability, possibility or pipe dream? Lancet. 342:879-880.

12. McCurry, K.R., D.L. Kooyman, C.G. Alvarado, A.H. Cotterell, M.J. Martin, J.S. Logan, and J.L. Platt. 1995. Human complement regulatory proteins protect swine-to-primate cardiac xenografts from humoral injury. Nat. Med. 1:423-427.

13. Kirk, A.D., R.A. Li, M.S. Kinch, K.A. Abernethy, C. Doyle, and R.R. Bollinger. 1993. The human antiporcine cellular repertoire: in vitro studies of acquired and innate cellular responsiveness. Transplantation (Baltimore). 55: 924-931.

14. Rollins, S.A., S.P. Kennedy, A.J. Chodera, E.A. Elliott, G.B. Zavoico, and L.A. Matis. 1994. Evidence that activation of human T cells by porcine endothelium involves direct recognition of porcine SLA and costimulation by por- cine ligands for LFA-1 and CD2. Transplantation (Baltimore). 57:1709-1716.

15. Murray, A.G., M.M. Khodadoust, J.S. Pober, and A.L.M. Bothwell. 1994. Porcine aortic endothelial cells activate human T cells: direct presentation of MHC antigens and costimulation by ligands for human CD2 and CD28. Immunity. 1:57-63.

16. Mueller, B.M., and R.A. Reisfeld. 1991. Potential of the scid mouse as a host for human tumors. Cancer Metastasis Rev. 10:193-200.

17. Segal, R., A. Globerson, H. Zinger, and E. Mozes. 1992. Induction of experimental systemic lupus erythematosus (SLE) in mice with severe combined immunodeficiency (scid). Clin. Exp. Immunol. 89:239-243.

18. Saeki, Y., T. Mima, S. Sakoda, H. Fujimura, N. Arita, T. Nomura, and T. Kishimoto. 1992. Transfer of multiple sclerosis into severe combined immunodeficiency mice by mononuclear cells from cerebrospinal fluid of the patients. Proc. Natl. Acad. Sci. USA. 89:6157-6161.

19. McCune, J., H. Kaneshima, J. Krowka, R. Namikawa, H. Outzen, B. Peault, L. Robin, C.C. Shih, E. Yee, and M. Lieberman. 1991. The scid-hu mouse: a small animal model for HIV infection and pathogenesis. Ann. Rev. Immunol. 9:399-429.

20. Torbett, B.E., G. Picchio, and D.E. Mosier. 1991. Hu-PBL-scid mice: a model for human immune function, AIDS and lymphomagenesis. Immunol. Rev. 124:139-164.

21. Namikawa, R., K.N. Weilbaccher, H. Kaneshima, E.J. Yee, and J.M. McCune. 1990. Long term human hematopoiesis in scid-hu mouse. J. Exp. Med. 172:1055-1063.

22. Dick, J.E., T. Lapidot, and F. Pflumio. 1991. Transplantation of normal and leukemic human bone marrow into immunodeficient mice: development of animal models for human hematopoiesis. Immunol. Rev. 124:25-43.

23. Krowka, J.F., S. Sarin, R. Namikawa, J.M. McCune, and H. Kaneshima. 1991. Human T cells in the scid-hu mouse are phenotypically normal and functionally competent. J. Immunol. 146:3751-3756.

24. Tery-Lehmann, M., and A. Saxon. 1992. Human mature T cells that are anergic in vivo prevail in scid mice reconstituted with human peripheral blood. J. Exp. Med. 175:503-516.

25. Hesselton, R.M., R.A. Koup, M.A. Cromwell, B.S. Graham, M. Johns, and J.L. Sullivan. 1993. Human peripheral blood xenografts in the SCID mouse: characterization of immunologic reconstitution. J. Infect. Dis. 168:630640.

26. Mosier, D.E., R.J. Gulizia, S.M. Baird, and D.B. Wilson. 1988. Transfer of a functional human immune system to mice with severe combined immunodeficiency. Nature (Lond.). 335:256-262.

27. Simpson, E., J. Farrant, and P. Chandler. 1991. Phenotypic and functional studies of human peripheral blood lymphocytes engrafted in SCID. Immunol. Rev. 124:97-111.

28. Shiroki, R., N.J. Poindexter, S. Woodle, M.S. Hussain, T. Mohanakumar, and D.W. Scharp. 1994. Human peripheral blood lymphocyte reconstituted severe combined immunodeficient (hu-PBL-SCID) mice: a model for human islet allograft rejection. Transplantation (Baltimore). 57:1555-1562

29. Ryan, U.S., and G. Maxwell. 1986. Isolation, culture and subculture of endothelial cells: mechanical methods. J. Tissue Culture Methods. 10:3-5.

30. Platt, J.L., M.A. Turman, H.J. Noreen, R.J. Fischel, R.M. Bolman, and F.H. Bach. 1990. An ELISA assay for xenoreactive natural antibodies. Transplantation (Baltimore). 49:1000-1001.

31. Grynkiewicz, G., M. Poenie, and R.Y. Tsien. 1985. A generation of $\mathrm{Ca}^{2+}$ indicators with greatly improved fluorescein properties. J. Biol. Chem. 260: $3440-3450$.

32. Holzknecht, Z.E., and J.L. Platt. 1995. Identification of porcine endothelial cell membrane antigens recognized by human xenoreactive natural antibodies. J. Immunol. 154:4565-4575.

33. Guilbert, B., G. Dighiero, and S. Avrameas. 1982. Naturally occurring antibodies against nine common antigens in human sera. I. Detection, isolation and characterization. J. Immunol. 128:2779-2787.

34. Dighiero, G., B. Guilbert, and S. Avrameas. 1982. Naturally occurring antibodies against nine common antigens in humans sera. II. High incidence of monoclonal Ig exhibiting antibody activity against actin and tubulin and sharing antibody specificities with natural antibodies. J. Immunol. 128:2788-2792.

35. Dighiero, G., P. Lymberi, J. Mazie, S. Rouyre, G.S. Butler-Browne, R.G. Whalen, and S. Avrameas. 1983. Murine hybridomas secreting natural monoclonal antibodies reacting with self antigens. J. Immunol. 131:2267-2272.

36. Prabhakar, B.S., J. Saegusa, T. Onodera, and A.L. Notkins. 1984. Lymphocytes capable of making monoclonal autoantibodies that react with multiple organs are a common feature of the normal B cell repertoire. J. Immunol. 133: 2815-2817.

37. Platt, J.L., and Z.E. Holzknecht. 1994. Porcine platelet antigens recognized by human xenoreactive natural antibodies. Transplantation (Baltimore). 57:327-335.

38. Carlsson, R., C. Martensson, S. Kalliomaki, M. Ohlin, and C.A.K. Borrebaeck. 1992. Human peripheral blood lymphocytes transplanted into SCID mice constitute an in vivo culture system exhibiting several parameters found in normal humoral immune response and are a source of immunocytes for the production of human monoclonal antibodies. J. Immunol. 148:1065-1071.

39. Markham, R.B., and A.D. Donnenberg. 1992. Effect of donor and recipient immunization protocols on primary and secondary human antibody re- 
sponses in scid mice reconstituted with human peripheral blood mononuclear cells. Infect. Immun. 60:2305-2308.

40. Sandhu, J., B. Shpitz, S. Gallinger, and N. Hozumi. 1994. Human primary immune response to SCID mice engrafted with human peripheral blood lymphocytes. J. Immunol. 152:3806-3813.

41. Saxon, A., E. Macy, K. Denis, M. Tory-Lehmann, O. Witte, and L. Braun. 1991. Limited B cell repertoire in severe combined immunodeficient mice engrafted with peripheral blood mononuclear cells derived from immunodeficient or normal humans. J. Clin. Invest. 87:658-665.

42. Abedi, M.R., B. Christensson, K.B. Islam, L. Hammarstrom, and C.I.E. Smith. 1992. Immunoglobulin production in severe combined immunodeficient (scid) mice reconstituted with human peripheral blood mononuclear cells. Eur. J. Immunol. 22:823-828.

43. Duchosal, M.A., S.A. Eming, P.J. McConahey, and F.J. Dixon. 1992. The hu-PBL-scid mouse model: long term human serologic evolution associated with the xenogeneic transfer of human peripheral blood leukocytes into scid mice. Cell. Immunol. 139:468-477.

44. Platt, J.L., R.J. Fischel, A.J. Matas, S.A. Reif, R.M. Bolman, and F.H. Bach. 1991. Immunopathology of hyperacute xenograft rejection in a swine-primate model. Transplantation (Baltimore). 52:214-220.

45. Tuso, P.J., D.V. Cramer, Y.D. Middleton, M. Kearns-Jonker, C. Yasunaga., C.A. Cosenza, W.C. Davis, G.D. Wu, and L. Makowka. 1993. Pig aortic endothelial cell antigens recognized by human IgM natural antibodies. Transplantation (Baltimore). 56:651-655.

46. Geller, R.L., R. Rubinstein, and J.L. Platt. 1994. Variation in expression of porcine xenogeneic antigens. Transplantation (Baltimore). 58:272-277.

47. Bach, F.H., M.L. Blakely, W.J. Van der Derf, B. Vanhove, K. Stuhl- meier, R. de Martin, and H. Winkler. 1994. Xenotransplantation: problems posed endothelial cell activation. Transplant. Proc. 26:1029-1030.

48. Bach, F.H., S.C. Robson, C. Ferran, H. Winkler, M.T. Millan, K.M Stuhlmeier, B. Vanhove, M.L. Blakely, W.J. van der Derf, E. Hofer, R.D. Martin, and W.W. Hancock. 1994. Endothelial cell activation and thromboregulation during xenograft rejection. Immunol. Rev. 141:5-30.

49. Platt, J.L., B.J. Lindman, S.L. Chen, S.L. Spitalnik, and F.H. Bach. 1990. Endothelial cell antigens recognized by xenoreactive human natural antibodies. Transplantation (Baltimore). 50:817-822.

50. Vaughn, H.A., P.L. Dabkowski, I.F.C. Mckenzie, and M.S. Sandrin. 1993. Biochemical analysis of pig xenoantigens detected by human antibodies. Transplant. Proc. 25:2919-2920.

51. Platt, J.L., G.M. Vercellottti, A.P. Dalmasso, R.M. Matas, J.S. Bolman, J.S. Najarian, and F.H. Bach. 1990. Transplantation of discordant xenografts: a review of progress. Immunol. Today. 11:450-456.

52. Williams, S.C., T. Umemoto, H. Kida, E.A. Repasky, and R.B. Bankert. 1992. Engraftment of human peripheral blood leukocytes into severe combined immunodeficient mice results in the long term and dynamic production of human xenoreactive antibodies. J. Immunol. 149:2830-2836.

53. Parker, W., D. Bruno, Z.E. Holzknecht, and J.L. Platt. 1994. Characterization and affinity isolation of xenoreactive human natural antibodies. J. Immunol. 153:3791-3803.

54. Saadi, S., and J.L. Platt. 1995. Transient perturbation of endothelial integrity induced by natural antibodies and complement. J. Exp. Med. 181:21-31.

55. Hynes, R.O. 1992. Integrins: versatility, modulation, and signaling in cell adhesion. Cell. 69:11-25. 